\title{
High Temperature Degradation by Erosion-Corrosion in \\ Bubbling Fluidized Bed Combustors
}

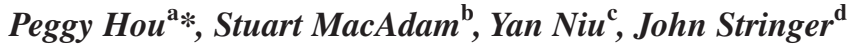 \\ ${ }^{a}$ Lawrence Berkeley National Laboratory, \\ 1 Cyclotron Rd. MS: 62-203 CA 94720 Berkeley, USA \\ ${ }^{\mathrm{b}}$ Data Preference Pte Ltd \\ 107A Sophia Road 228172 Singapore \\ ${ }^{\mathrm{c}}$ Institute of Metal Research, Chinese Academy of Sciences \\ Wencui Road 62, 110015 Shenyang, China \\ ${ }^{\mathrm{d}}$ Electric Power Research Institute \\ 3412 Hillview Ave, CA 94304 Palo Alto, USA
}

Received: September 2, 2002; Revised: September 4, 2002

\begin{abstract}
Heat-exchanger tubes in fluidized bed combustors (FBCs) often suffer material loss due to combined corrosion and erosion. Most severe damage is believed to be caused by the impact of dense packets of bed material on the lower parts of the tubes. In order to understand this phenomenon, a unique laboratory test rig at Berkeley was designed to simulate the particle hammering interactions between in-bed particles and tubes in bubbling fluidized bed combustors. In this design, a rod shaped specimen is actuated a short distance within a partially fluidized bed. The downward specimen motion is controlled to produce similar frequencies, velocities and impact forces as those experienced by the impacting particle aggregates in practical systems. Room temperature studies have shown that the degradation mechanism is a three-body abrasion process. This paper describes the characteristics of this test rig, reviews results at elevated temperatures and compares them to field experience. At higher temperatures, deposits of the bed material on tube surfaces can act as a protective layer. The deposition depended strongly on the type of bed material, the degree of tube surface oxidation and the tube and bed temperatures. With $\mathrm{HCl}$ present in the bed, wastage was increased due to enhanced oxidation and reduced oxide scale adherence.
\end{abstract}

Keywords: Fluidized bed combustors, oxidation, erosion, $\mathrm{HCl}$, carbon steel

\section{Introduction}

The fluidized bed combustion of coal or other fuels as an energy production technology has received widespread usage. The excellent solids mixing in these reactors gives a number of advantages over conventional combustion techniques. The results are more efficient combustion at a lower temperature so as to reduce $\mathrm{NO}_{\mathrm{x}}$ formation and the ability to reduce sulfur emissions by adding into the bed a sorbent material, such as limestone $\left(\mathrm{CaCO}_{3}\right)$. One of the approaches to these systems is a bubbling fluidized bed, where the gas velocity in the bed is only a little greater than the minimum velocity required to fluidize it; the excess gas flow appears as voids resembling bubbles in a bed which is relatively

*e-mail: pyhou@lbl.gov

Presented at the International Symposium on High Temperature Corrosion in Energy Related Systems, Angra dos Reis - RJ, September 2002. dense. Despite the widespread usage of fluidized bed combustors (FBCs), there is a problem in that both the walls of the combustor and the in-bed heat exchanger tubes in bubbling beds may suffer loss of section. The term 'wastage' is commonly used for this phenomenon, which is generally accepted to be a result of erosion or abrasive wear that may be accelerated by oxidation or high-temperature corrosion ${ }^{1-3}$.

The wastage of heat-exchanger tubes in bubbling FBCs has been an area of interest for many years. The practical problem is that wear rates are very variable from unit to unit for reasons that are not clear. Furthermore, small operational changes often can cause large changes in wear 
behavior, again for reasons that have proved elusive. The use of Cl-containing coals, for example, is one key area with conflicting plant and laboratory results ${ }^{4-9}$. To resolve these issues, it is desirable to have some knowledge of the mechanisms of tube wastage, and to identify the relative importance of various factors in a FBC environment that may contribute to the wastage process. To achieve this, a special test rig was constructed at Berkeley to study the erosion and corrosion phenomena in a simulated FBC environment where the conditions are known and controllable.

The Berkeley test rig was built ${ }^{10-12}$ based on the belief that the energetic process within the bed capable of generating the kind of damage observed in practice is the impact of dense packets of bed material on the lower parts of the tubes ${ }^{13-16}$. These packets may be the wakes of rising bubbles within the bed. They may also result from the cooperative motion of large volumes of the bed generating a process resembling cavitation beneath the tubes. The wakes strike the bottoms of the tubes with a considerable force, which is easily detected and measured by appropriate sensors ${ }^{17-18}$, at least for beds operating at atmospheric pressures. Cold model studies have shown that upon bubble collapse, a block of essentially unfluidized bed particles is thrown against the tube bottom, and then drops away or slides upward across its surfaces ${ }^{19-20}$.

To achieve such conditions in a laboratory, a horizontally held cylindrical specimen was allowed to actuate a short distance vertically within a minimally fluidized bed ${ }^{10-12,21}$. The downward specimen motion is controlled to produce similar frequencies $(0.25-2.75 \mathrm{~Hz})$, velocities $(0.5-2 \mathrm{~m} / \mathrm{s})$ and impact forces $(100-600 \mathrm{~N})$ as those caused by the impacting particle aggregates in practical bubbling fluidized beds (BFBCs). Typically, the specimen is in motion for between 20 and $40 \mathrm{~ms}$. Between these periods of high particle loading, a relatively long period of inaction follows. This simulates the intermittent nature of the aggregate impacts found in practical situations.

The first rig was built to operate at room temperature. Results from these earlier tests verified the similarity in wastage behavior obtained from the actuation process of the rig and from BFBC cold tests ${ }^{10-12}$. The mechanism of wastage was identified to be that of low cycle fatigue resulting from three body abrasion ${ }^{22}$. A high temperature rig was later constructed so that operations at bed temperatures up to $900{ }^{\circ} \mathrm{C}$ became possible, and the entire system utilized a PC-based data acquisition, control, and analysis system ${ }^{23-24}$. The ability to internally cool the specimen to achieve a temperature difference between the bed and the specimen surface was later added to the high temperature rig, by passing water, air or a mixture of the two through the inside of the tube specimen ${ }^{25}$. In doing so, a reaction tube $18 \%$ larger in diameter was installed in order to accommodate the fixtures that connected the cooling lines to the ends of the speci- men. Details of the coolant supply and temperature measurements of the tube outer and inner surface can be found in reference 25 . These fixtures were later taken down and the apparatus was further modified to add $\mathrm{HCl}$ gas to the fluidizing air $^{26}$.

The purpose of this paper is to summarize the results that have been obtained from the high temperature rig simulations. The main focus is placed on tests performed at different temperatures with and without the presence of $\mathrm{HCl}$ in the bed. Emphases are placed on the effect of temperature, bed condition and bed material deposits on wastage.

\section{Experimental Procedures}

A schematic drawing of the high temperature rig that is presently in operation is shown in Fig. 1. A single specimen

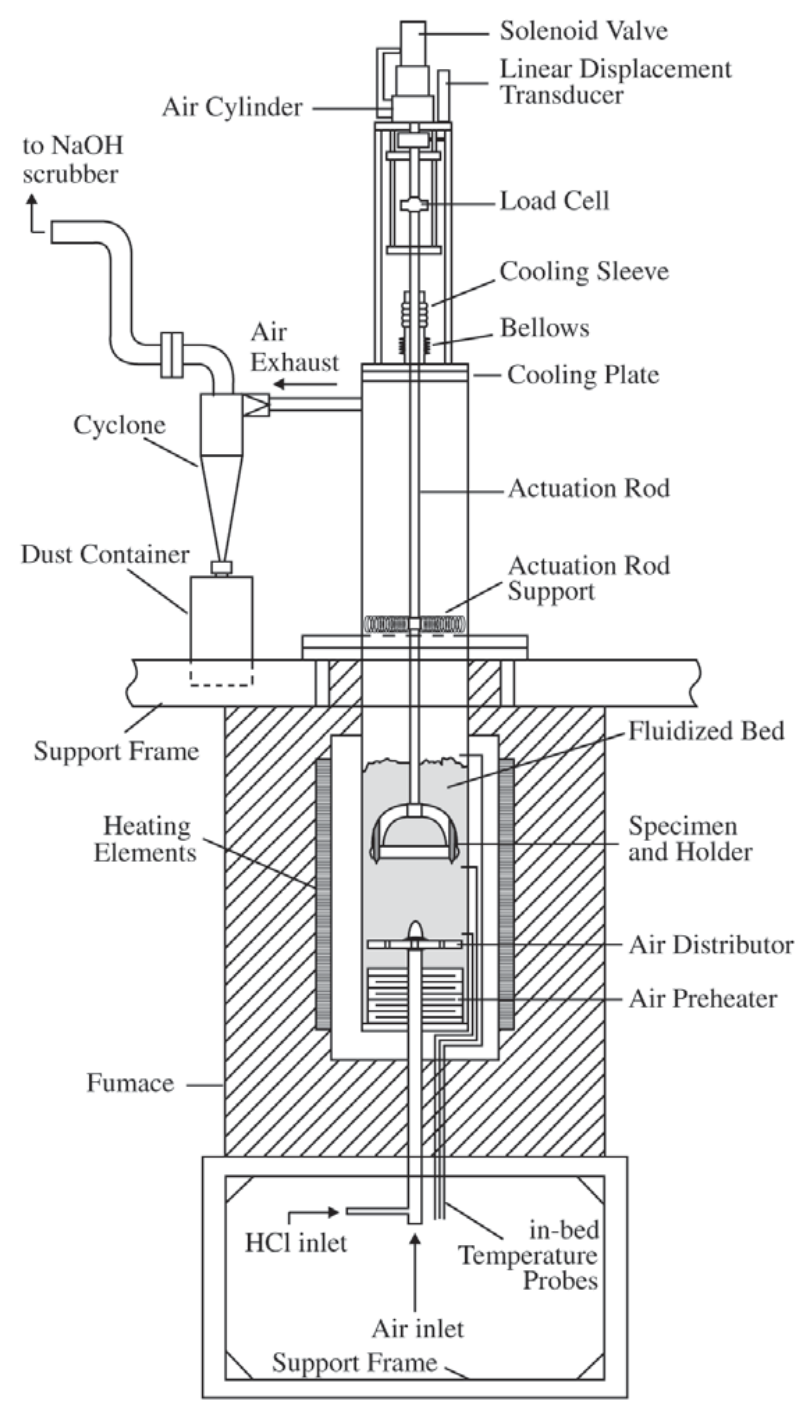

Figure 1. Schematic of the Berkeley laboratory erosion test rig. 
is held horizontally in a stirrup that is immersed in a partially fluidized bed of sand particles. During a test, the specimen and holder assembly, which is actuated via an air cylinder, is plunged quickly downward within the bed a distance of $1 \mathrm{~cm}$. It is then slowly drawn up to its rest position; this cycle is repeated at a frequency of $1 \mathrm{~Hz}$.

The fluidizing air velocity is set and controlled with a mass flow controller. The air enters at the bottom, passing through a pre-heater, and into the bed through a number of downward facing orifices on the air distributor. The impact environment of the rig is one that the underside of the specimen experiences a periodic, brief impact of an aggregate of bed particles as the specimen is actuated. From the forces exerted onto the specimen and the distance it travels within the bed, an impact energy per stroke can be calculated. Since the impact energy against the rod surface is determined by the resistance of the bed material, small changes in the fluidizing condition can strongly affect the impact energy. The desired energy level is therefore set at the start of a test and is monitored and controlled automatically throughout the test, by small adjustments in the gas flow velocity, to within $\pm 10 \%$ about the set value.

When testing the effect of chlorine, $50-400 \mathrm{ppm} \mathrm{HCl}$ gas was introduced into the bed immediately before the distributor from a cylinder of $\mathrm{HCl}$ and $\mathrm{N}_{2}$ mixture. The bed material used was commercial silica sand with an average size of $800 \mu \mathrm{m}$ that also contained some $\mathrm{K}, \mathrm{Ca}$ and $\mathrm{Al}$-mixed silicates. New bed particles underwent a conditioning process prior to testing, where they were fluidized at a relatively high velocity for a long period to reach a stable particle shape and size. The same conditioned bed particles were used for multiple tests. Between tests, about $2.5 \%$ of the bed material was removed and replaced with fresh particles. The bed was then fluidized vigorously for about $1 \mathrm{~h}$ to remove excess fine dusts in the bed and to mix in the replenished material. In order to achieve a $2.5 \mathrm{~J} /$ stroke energy level (maximum force of $300 \mathrm{~N}$ ) on the specimen, the bed was partially fluidized at about $70 \%$ of the fluidizing velocity. Tests were conducted under the "low" or "high-dust" conditions ${ }^{24}$ where every 4 or $10 \mathrm{~min}$ the air velocity was increased by 1.7 times for $20 \mathrm{~s}$ to thoroughly mix the bed and to reduce the fine dust particles in it. Three thermocouples were placed at locations above the distributor, immediately below the bed and next to the specimen to monitor and control the bed temperature.

Different metals and alloys were used in the early tests at room temperature to characterize the rig and distinguish the wear mechanism in the absence of corrosion ${ }^{10,11}$. Later tests at elevated temperatures concentrated on 1018 mild steel rods ${ }^{24}$ or tubes ${ }^{25}$ that were 100 or $108 \mathrm{~mm}$ long and $19 \mathrm{~mm}$ in diameter. Before testing, the specimen surface was machined on a grinder to produce a fine surface finish of about $1 \mu \mathrm{m}$. Specimens were heated in the bed to the desired operating temperature. The test began by starting the actuation and introducing the $\mathrm{HCl}$ gas when needed. Total test duration was between $40-70 \mathrm{~h}$, after which the $\mathrm{HCl}$ flow would be stopped and the airflow was increased to quickly cool the bed.

The degree of wastage was determined by surface profilometry around the entire specimen surface, but most of the time, concentrating only on the lower half. Measurements were made relative to a center region of the specimen that was masked during testing. The morphology of the specimen surface around the circumference was characterized by scanning electron microscopy (SEM) both in cross sections and in surface views. The surface of bed particles was also closely examined by SEM. Energy dispersive $\mathrm{X}$-ray spectrometry (EDS) and X-ray diffraction were used to determine the species present in the bed particles, the deposit layer and the oxide that formed at higher temperatures.

\section{Results and Discussions}

\subsection{Temperature dependence of wastage}

The erosion behavior of 1018 mild steel at temperatures from ambient to $540{ }^{\circ} \mathrm{C}$ was studied. A typical wastage distribution about the lower half of the specimen, measured in degrees that are referenced to $0^{\circ}$ at the rod top, is shown in Fig. 2. The maximum material loss is between $25^{\circ}$ and $30^{\circ}$ on either side of the bottom. Near the sides from the bottom, there was a thickness increase caused by the buildup of a continuous agglomerated deposit layer. The layer consisted of the bed material and its thickness increased with increasing bed temperatures. Over the entire top half of the specimens, there was never any wastage, but there existed a

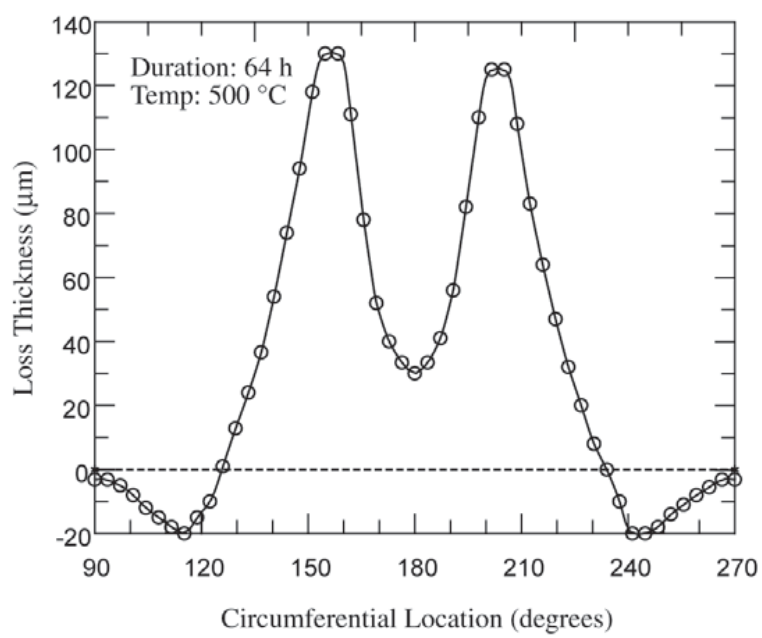

Figure 2. Typical circunferential distribution of wastage over the bottom half of the specimen rods, where the bottom is at $180^{\circ}$. 
continuous measurable oxide layer at temperatures of $300{ }^{\circ} \mathrm{C}$ and above.

This wear profile, where the maximum wastage occurred to the sides of the bottom, is observed in cold models, and occasionally in practical FBCs where entrained flow prevails, and has been labeled a "Type A" wear pattern" ${ }^{27}$. In the majority of cases, however, the maximum wear in FBC is found at the bottom of the tube, decreasing away from this location on either side to zero close to tube mid-section, labeled a "Type B" wear pattern ${ }^{27}$. The fact that this rig does not produce the Type B pattern was found to be due to the constrained vertical motion in the bed. When the constraint is relaxed, as shown by a computer simulation study ${ }^{28}$ and by experiments ${ }^{21}$, the Type B wear pattern more commonly found in bubbling beds could be generated.

The maximum wastage rate for the Type A wear pattern is plotted in Fig. 3 as a function of specimen temperature. Three sets of data were obtained under the "low-dust" condition, where the frequency of high air flow through the bed was greater such that the amount of particle fines retained in the bed during testing was relatively low ${ }^{24}$. One set of test was done in the "high-dust" condition with more fine particles remaining in the bed. The data include results obtained using three different batches of commercial sand. While most of the sand contained $\mathrm{SiO}_{2}$ particles, some $\mathrm{K}$, $\mathrm{Ca}$ and $\mathrm{Al}$ silicates were always present. The relative amount of these softer materials increased from batches 1 - 3 from about 6,16 to $22 \%$ respectively. At low temperatures, below $300{ }^{\circ} \mathrm{C}$, the wastage rates were between $0.9-3.5 \mathrm{~mm} / \mathrm{yr}$, which are similar to practical experience, and they were slightly lower when the bed contained larger amounts of silicates. In the intermediate temperature range, around

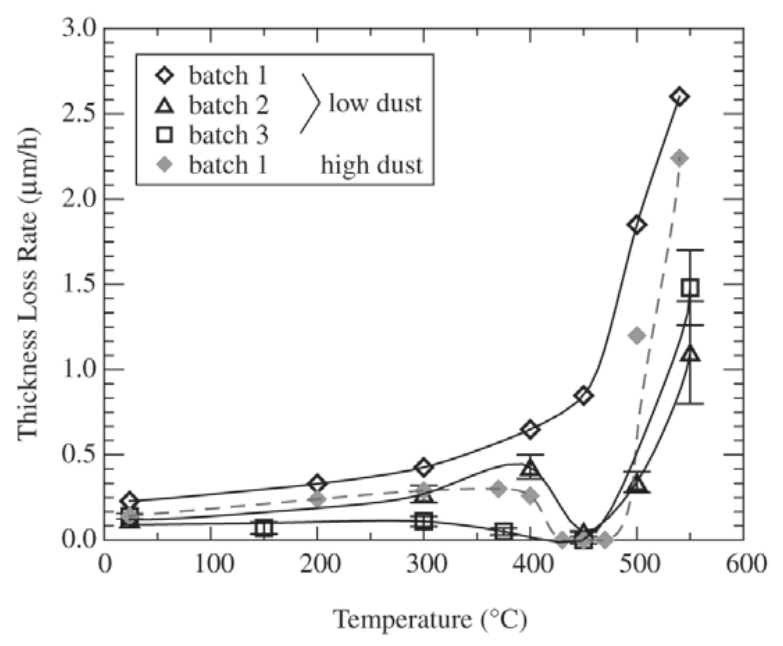

Figure 3. Maximum wastage rates as a function of specimen temperature. Three batches of sand were used, with increasing concentrations of $\mathrm{K}, \mathrm{Ca}$, and $\mathrm{Al}$ containing silicates.
$450{ }^{\circ} \mathrm{C}$, the rate could either drop to zero or increase quickly with temperature. This transition from wastage to protection occurred when the bed contained more silicates and when testing were performed under the "high-dust" condition. A similar drop in wastage rate at these intermediate temperatures has been found in some practical applications but not all ${ }^{29}$. Above $475^{\circ} \mathrm{C}$, in the high temperature regime, wastage rates increased with temperature under all conditions.

Representative SEM images of the worn surfaces and cross sections from the wasted regions at low, medium and high temperature regimes are shown in Figs. 4 and 5. On all surfaces, wear scars that were made by particle impacts are apparent. At the low temperatures, the base of the scars consisted mainly of metal. Deposited bed material often existed at the ends of these scars in loose agglomerations, and as solid compressed clumps on the surrounding surface (Fig. 4a). Metal within the top surface region was deformed into thin overlapping foils that were aligned in the direction of general particle flow over the surface (Fig. 5a), similar to that observed by Levy ${ }^{30}$. Bed materials were found between the foils and at some locations of the surface, while other regions had metal exposed at the surface. In the high temperature regime, the wear scar grooves were shallow and did not appear to extend to the base metal (Fig. 4c). Small patches of spallation, such as the region part way along the scar, were often found. There was little metal deformation; instead an oxide layer of 2 to $5 \mu \mathrm{m}$ existed intermittently over the surface, and much of the oxide cracked into segments (Fig. 5c). In regions where the oxide was absent, the metal surface was exposed. Everywhere on the wear surface, there was insignificant deposition of the bed material. In contrast, a thick deposit layer existed over the wasted region (Fig. 5b) on specimens tested at the intermediate temperatures that showed protective behavior. The deposit was over an oxide layer averaging $2 \mu \mathrm{m}$ thick, and consisted of discrete micron sized bed particles held in a sintered agglomeration of sub-micron particles. The impact seen on the surface (Fig. 4b) did not gouge into the metal but only compacted the loosely packed deposit layer.

Results shown so far clearly indicate that wastage can be reduced by a deposit layer that forms on the specimen surface. This type of deposit is consistent with experience in practice, in that the higher temperature metal surfaces are usually covered with a dense adherent coating, with a very fine grain size ${ }^{31}$. For the 1018 steel reported here, deposits were only found at intermediate temperatures where oxidation became more important, and when the bed contained either higher levels of fine dust, greater amounts of soft silicates, or as another study showed, an addition of $1 \mathrm{vol} \% \mathrm{CaSO}_{4}{ }^{21}$. When a 304 stainless steel was tested ${ }^{21}$, protection was only found above $650{ }^{\circ} \mathrm{C}$ with $1 \% \mathrm{CaSO}_{4}$ added in the bed, suggesting the importance of a sufficiently thick surface oxide layer and its interaction with the bed 

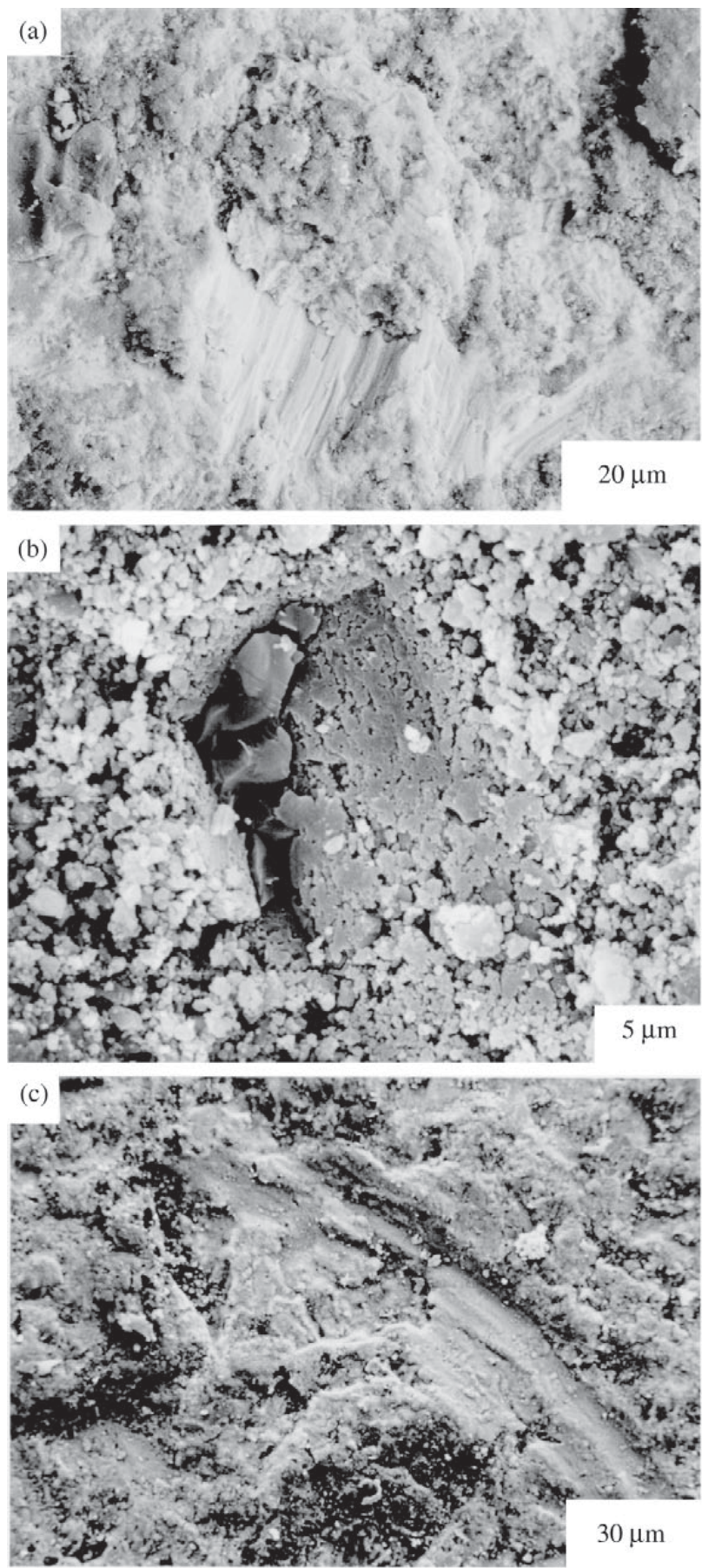

Figure 4. Backscattered SEM images of impact scars in the maximum wastage regions on specimens tested with batch 1 sand at: a) $300{ }^{\circ} \mathrm{C}$, low dust condition; b) $450{ }^{\circ} \mathrm{C}$, high dust condition; c) $500{ }^{\circ} \mathrm{C}$, low dust condition.

material in developing the protective layer.

To better understand the process of deposit formation, bulk bed particles were first examined carefully under the
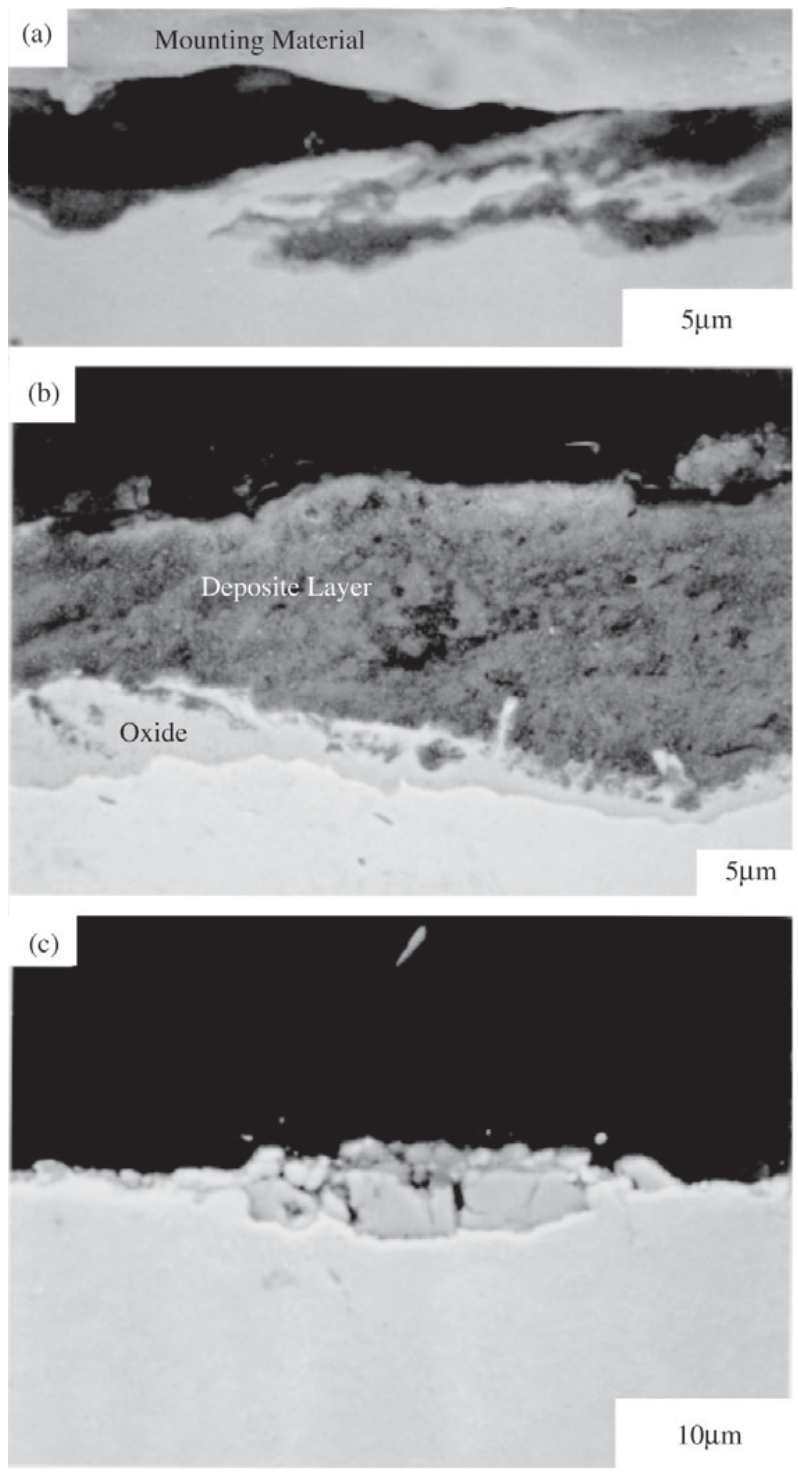

Figure 5. Backscattered SEM images of cross sections from maximum wastage regions on specimens tested with batch 1 sand at (a) $300{ }^{\circ} \mathrm{C}$, low dust condition; (b) $450{ }^{\circ} \mathrm{C}$, high dust condition; and (c) $500{ }^{\circ} \mathrm{C}$, low dust condition.

SEM, then a specimen surface was observed in the earliest stage of deposition. Fig. 6a shows a bed particle taken at the conclusion of a test that showed protective behavior. The particle is partially encased by a loosely adherent layer that spalled easily upon cooling. At higher magnifications, the encased layer was found to consist of fine bed particles that had agglomerated together to form micron sized clusters. Scoring marks on the encased layer suggest that it was formed and compacted by compression that probably resulted from 

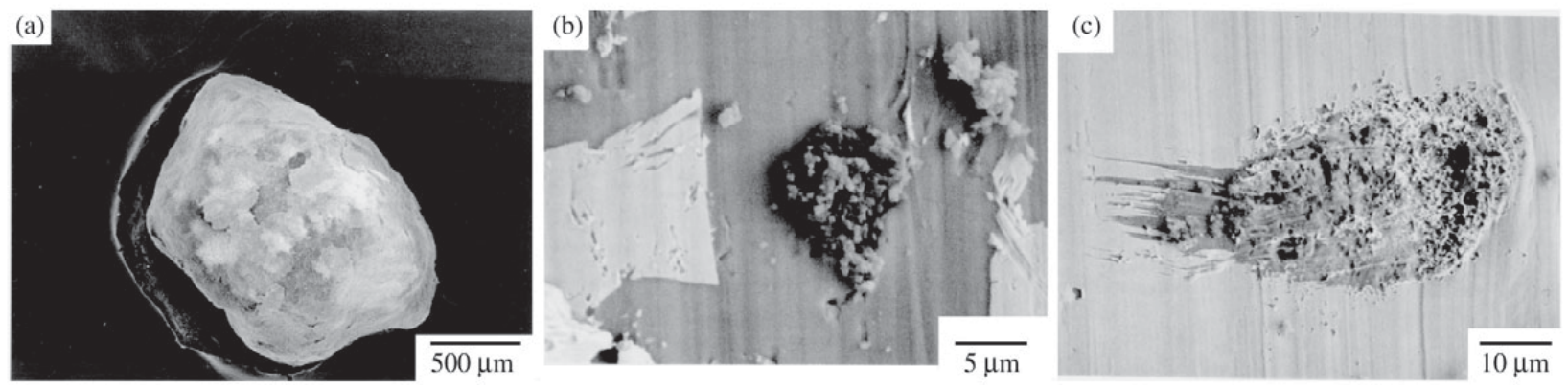

Figure 6. a) SEM image of a bed particle under high dust condition; b) and c) show depositions of fine bed particles on a gold-coated specimen tested for $30 \mathrm{~s}$ at $300{ }^{\circ} \mathrm{C}$

impacts with the specimen or with other bulk bed particles. The encasement increased with temperature, and more obviously, with the dust concentration in the bed ${ }^{24}$. Although gross metal deformation was not essential for deposition to occur, as seen in (Fig. 6b), more deposition occurred at locations of significant impacts, as in (Fig. 6c). Protective deposit layer, therefore, is believed to have formed by the transfer of agglomerated layer segments that were first formed on the bulk bed particles. The transferred clumps when first deposited on the specimen are relatively loosely bonded, but are compacted with repeated impacts, and a dense continuous layer is formed. The fact that spallation of the deposit and oxide layer occurred at the oxide/metal interface, with the overlying deposit remaining attached to the oxide, suggests a relatively strong bond between the oxide and the deposit. It also implies that the initial interaction between the fine particles and the oxide layer may be important.

At higher temperatures, the wastage rate became dominated by oxidation, which itself was affected by the erosion process similar to the wear enhanced oxidation regime described by Rishel et al. ${ }^{32}$. Scales that form to a critical thickness would spall as a result of repeated impacts followed by oxide re-growth. Whether a deposit layer forms on the specimen surface to render protection against wastage seems to depend on two competing processes; one is the growth of the oxide scale and the other the formation of a dense bed material layer on the specimen surface. If the deposit layer can build up in thickness faster than the erosion processes, it will protect the underlying metal from wastage. The condition at which this layer forms depends on the amount of fine dust particles retained in the bed, which is closely related to the composition of the bed, the specimen and bed temperatures and the oxidation rate of the specimen.

\subsection{Effect of $\mathrm{HCl}$ on wastage}

The amount of chlorine in coals can vary widely with location ${ }^{33}$ and usually increases with mining depth ${ }^{34}$. Most of the chlorine is associated with the organic matter in the coal. Part of it occurs as sodium chloride dissolved in pore water and the rest is concentrated in micropores, probably associated with hydrogen ${ }^{35}$. Upon heating of the coals, part of the chlorine is released as $\mathrm{HCl}^{36}$. Based on the rate of release during combustion ${ }^{37}$ and from plant measurements in boilers, about $80 \mathrm{ppm}$ of $\mathrm{HCl}$ is released for each $0.1 \%$ $\mathrm{Cl}$ in the coal.

Using the batch 3 sand under low dust condition, the effect of $50 \mathrm{ppm} \mathrm{HCl}$ on wastage was studied from the ambient temperature to $400{ }^{\circ} \mathrm{C}$, and the effect of varying the $\mathrm{HCl}$ content up to $400 \mathrm{ppm}$ was studied at $300{ }^{\circ} \mathrm{C}$. The maximum wastage rates as a function of test temperature and $\mathrm{HCl}$ content are shown in Figs. 7 and 8 respectively. The wastage profile was not substantially altered by the presence of $\mathrm{HCl}$, in that the maximum still occurred at $20-30^{\circ}$ away from the bottom and the profile was symmetrical on either side of it. The only difference was the higher rate and a wider wastage region due to the lack of a deposit layer ${ }^{38,39}$. Wear scars on the wastage area showed that materials loss still involved cutting by the impacting particle as it traveled on the specimen surface. Below $200{ }^{\circ} \mathrm{C}$, the effect on the wastage rate was minimal with an increase of only a factor of two. At higher temperatures the rate drastically increased, and it was 8 and 15 times greater at 300 and $400{ }^{\circ} \mathrm{C}$ respectively. This degree of increase is similar to the order of magnitude higher wastage observed in the TVA's pilot plant when a high chlorine coal was used ${ }^{4}$.

The maximum wastage clearly increased with higher $\mathrm{HCl}$ concentration. The increase was fast with initial increase in $\mathrm{HCl}$, then became more gradual and slowly approached a steady state level. After testing in $\mathrm{HCl}$, the bed material was apparently contaminated, because further testing in the bed without any flow of $\mathrm{HCl}$ gas resulted in an accelerated wastage rate. According to the dosage dependence shown in Fig. 8, this contamination is equivalent to an $\mathrm{HCl}$ concentration of about $20 \mathrm{ppm}$. The fact that $\mathrm{HCl}$ can remain in the bed and cause a noticeable increase in wastage raises some practical concerns, particularly with down 
time corrosion where $\mathrm{HCl}$ can react with moisture to cause severe pitting attack.

Microstructural and compositional characterization of the specimens showed that under all $\mathrm{HCl}$ containing test conditions, $\mathrm{Cl}$ was detected on the specimen surface and its concentration was higher near the scale/alloy interface. Specimens tested with $\mathrm{HCl}$ addition showed significantly greater scale spallation than those tested without. The phenomenon was more severe with higher testing temperatures

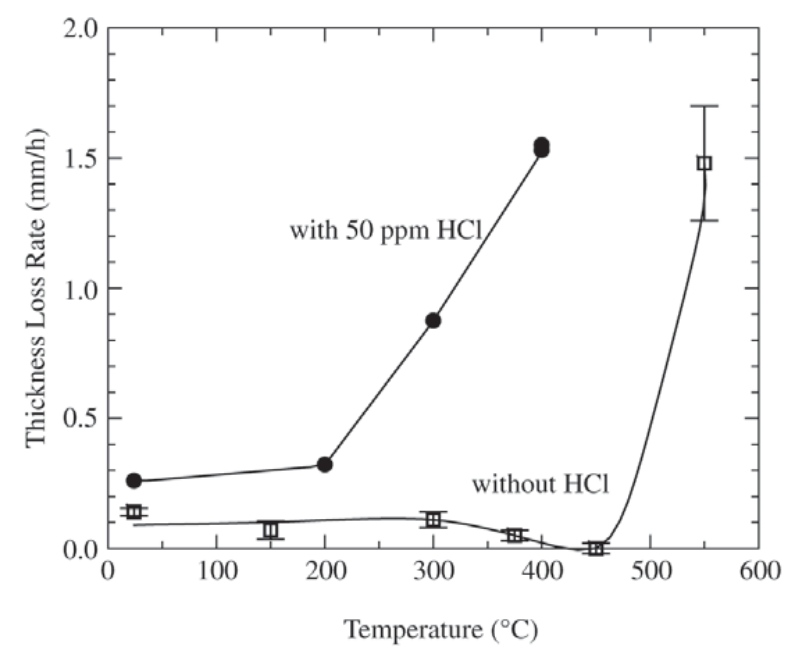

Figure 7. Effect of $\mathrm{HCl}$ on the maximum wastage rates as a function of specimen temperature. and occurred only on the top half of the specimen where there was no impact. Fig. 9 shows the top surface of a $400{ }^{\circ} \mathrm{C}$ sample. Most of the scale had spalled leaving a thin layer of iron oxide on the metal. In this thin oxide layer a small amount of chlorine was detected. Cl-rich nodules 5 - $40 \mu \mathrm{m}$ in size were numerous on the spalled areas. The amount of $\mathrm{Cl}$ in the scale, however, decreased with the length of time it was stored after testing, as $\mathrm{FeCl}_{2}$ slowly transformed to $\mathrm{Fe}_{2} \mathrm{O}_{3}$ in the presence of moisture ${ }^{38}$. The scale thickness on

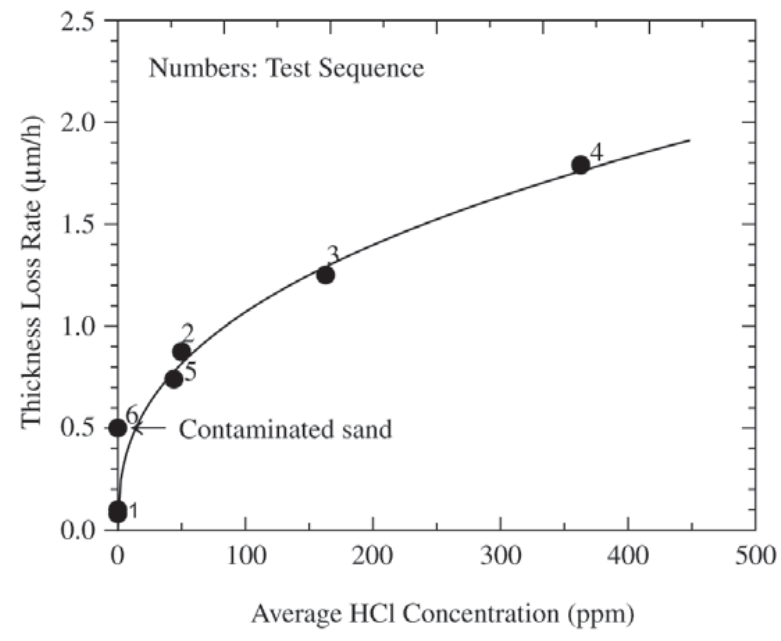

Figure 8. Effect of $\mathrm{HCl}$ dosage on the maximum wastage rate at $300{ }^{\circ} \mathrm{C}$.

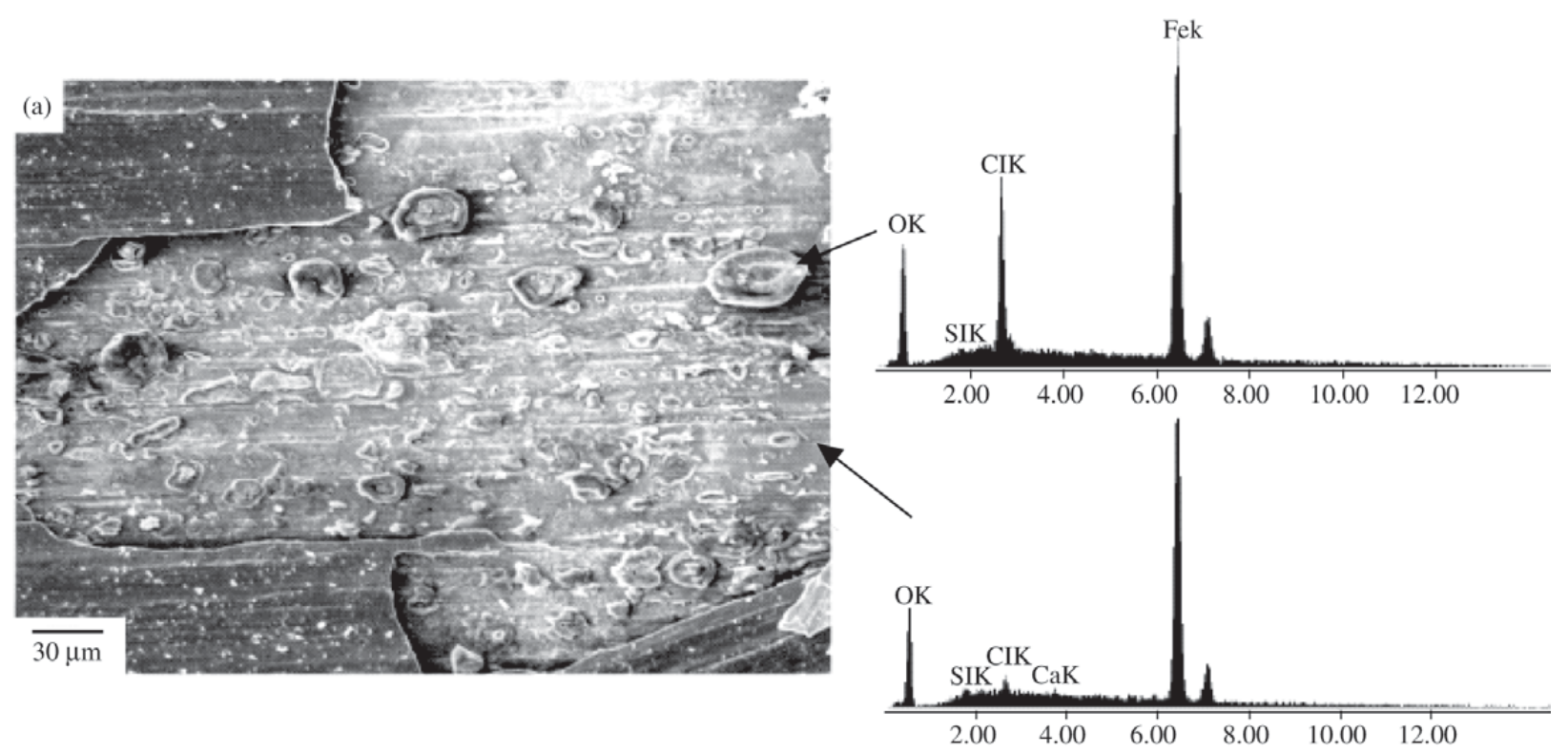

Figure 9. SEM micrograph of the top surface (near $0^{\circ}$ ) on a specimen tested at $400{ }^{\circ} \mathrm{C}$ for $24 \mathrm{~h}$ with $50 \mathrm{ppm} \mathrm{HCl}$. EDS analyses show compositions of the nodule and the thin oxide on the alloy surface. 

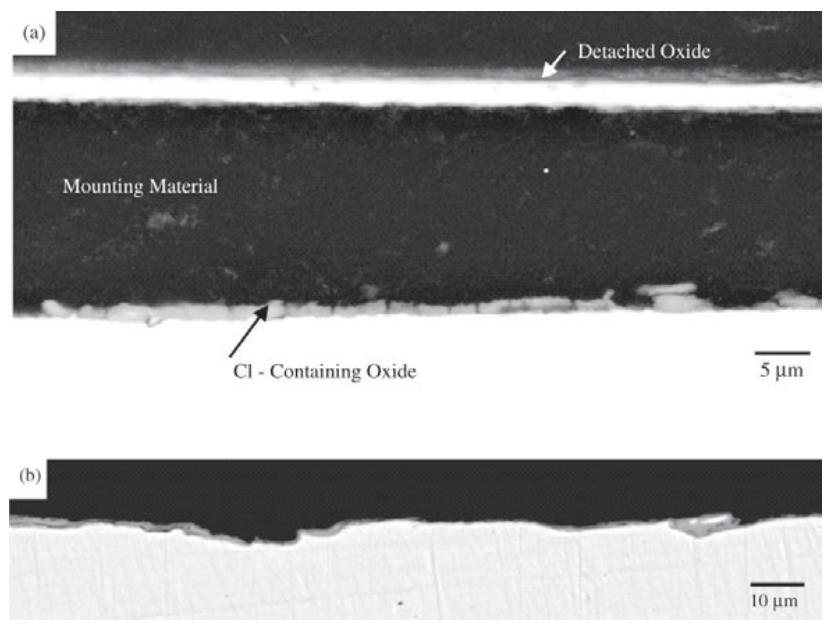

Figure 10. Backscattered SEM images of cross-sectioned specimen tested at $400{ }^{\circ} \mathrm{C}$ in $50 \mathrm{ppm} \mathrm{HCl}$. a) From the surface that underwent static oxidation; b) from the maximum wastage region.

the worn surface was always thinner than on the top where only static oxidation occurred; an example is given in Fig. 10. Under static oxidation, Fig. 10a, a 3 - $4 \mu \mathrm{m}$ thick but non- adherent oxide layer that consisted mainly of $\mathrm{Fe}_{3} \mathrm{O}_{4}$ formed on the surface and a thin layer of Cl-containing scale was present at the interface. On the worn region (Fig. 10b), the scale that remained was much thinner and cuts into the alloy caused by the wear process were also apparent.

Comparing the static oxide thickness on the top half of the specimen indicated that scales formed in the presence of $\mathrm{HCl}$ were significantly thicker. The oxide growth rates increased by nearly an order of magnitude ${ }^{39}$. It is not surprising that $\mathrm{HCl}$ enhanced oxidation rate and reduced scale adherence. The fact that its presence can increase oxidation rates is well known ${ }^{40-42}$, and $\mathrm{Cl}$ at the scale/alloy interface is generally believed to weaken $\mathrm{it}^{43,44}$. $\mathrm{HCl}$ probably gained access to the scale/metal interface by passing along naturally occurring micro-cracks and pores ${ }^{45}$ in the oxide scales. In the impacting condition of this test rig, such micro-cracks must be numerous on the bottom half of the specimen. Once at the metal surface, $\mathrm{HCl}$ can react with the substrate to form $\mathrm{FeCl}_{2}$.

The combined increase in the oxidation rate and reduction in the scale adherence in the presence of $\mathrm{HCl}$ is believed to have caused the high wastage rates at elevated temperatures. Under these conditions, the wastage process took place by the constant removal and continued growth of the oxide scale. The end result was a higher wastage rate caused by a faster scaling rate. The ease of scale spallation due to a poorer adhesion should further assist the oxide removal process. It is not entirely clear why less deposition occurred when testing involved $\mathrm{HCl}$; only partial layers were observed at
$400{ }^{\circ} \mathrm{C}$. In light of the discussion given in the previous section, the most probable reason is that the higher oxidation rate and the less adherent nature of the oxide scales competed with the development of this deposit layer.

\section{Conclusions}

The effect of temperature on the wastage of in-bed 1018 tubes, studied using a laboratory rig that simulates dense particle impact conditions in bubbling fluidized bed combustors, showed variable temperature dependence with slight changes in the bed material. At temperatures up to about $350{ }^{\circ} \mathrm{C}$, wastage was predominantly caused by abrasion with a very low oxidation component. The rate was insensitive to specimen material, but more so to bed composition. Above $500{ }^{\circ} \mathrm{C}$, wastage was high and was clearly controlled by oxidation, where an oxide layer would grow to a limiting thickness, spall under impact, and then reform. At intermediate temperatures, $400-500{ }^{\circ} \mathrm{C}$, wastage was very sensitive to the level of fine sub-micron dust within the bed and to the bed composition. Rapid decrease in wastage occurred when the condition allowed the development of a protective deposit layer that consisted of sub-micron deformable bed particles on the specimen surface. These particles deposited on bulk bed particles to form an encasing layer. This material was then transferred to the specimen surface during particle impact.

The presence of $50-400 \mathrm{ppm} \mathrm{HCl}$ in the bed increased wastage rates at all tested temperatures. With $50 \mathrm{ppm}$, the rates were 2 - 3 times higher below $200{ }^{\circ} \mathrm{C}$, but increased by 8 to 15 times at 300 and $400{ }^{\circ} \mathrm{C}$ respectively. A strong dosage effect was observed at $300^{\circ} \mathrm{C}$ with the greatest increase in wastage at the initial increase in $\mathrm{HCl}$ concentration. The wear characteristics were not changed by the presence of $\mathrm{HCl}$. The high rates observed at elevated temperatures were the result of accelerated oxidation and reduced scale adhesion. Testing with $\mathrm{HCl}$ also caused contamination of the bed material that affected wastage in subsequent tests.

\section{References}

1. Stringer, J. Current information on metal wastage in fluidized bed combustors, Proc. 9th Int. Conf. on Fluidized Bed Combustion, Boston, MA, May 1987, ed. J. P. Mustonen, ASME, New York, NY, p. 685-696, 1987.

2. Stringer, J.; Stallings, J.W.; Wheeldon, J. M. Wastage in bubbling fluidized-bed combustors: an update, Proc. 10th Int. Conf. on Fluidized Bed Combustion, San Francisco, CA, April 30 - May 3, 1989, ed. A. M. Manaker, ASME, New York, NY, p. 857-862, 1989.

3. Stallings, J.W.; Stringer, J. Mechanim of in-bed tube wastage in fluidized-bed combustors, Proc. CorrosionErosion-Wear of Materials at Elevelated Temperature, ed. A. V. Levy, Berkeley, CA, Jan. 31-Feb. 2, paper 19, 
1990.

4. Vincent, R.Q.; Poston, J.M.; Smith, B.F. Erosion Experience of the TVA 20-MW AFBC Boiler, in Proc. 9th Inter. Conf. on FBC, p. 672-684, ed. J. P. Mustonen, ASME, 1987.

5. Vincent, R.Q.; Canonico, D.A.; Wheeldon, J.M. An Evaluation Program for Metal Wastage in Fluidized Bed Combustors, in Proc. 10th Inter. Conf. on FBC, p. 927-935, ed. A. M. Manaker, AIME 1989.

6. Oakey, J.E.; Minchener, A.J.; Hodges, N.J. The Use of High Chlorine Coals in Industrial Boilers, in Chlorine in Coals, p. 251-273, ed. J. Stringer and D. D. Banerjee, Elsevier, N.Y., 1991.

7. Sethi, V.K.; Barber, S.A.; Sherman, S.K.; Gonzalez, R.A.; Puentes, E.; Stencel, J.M. Wear-Corrosion Synergism in Chlorine-Containing Coal Combustrion Environments, in Proc. 10th Inter. Conf. on Fluidized Bed Combustion, p. 563-573, ed. A. M. Manaker, ASME, 1989.

8. Vincent, R.Q.; Manaker, A.M. Effect of Chlorine Content on Materials Exposed in Coal Fired Fluidized Bed, in Chlorine in Coal, p. 389-409, ed. J. Stringer and D. D. Banerjee, Elsevier, N.Y., 1991.

9. Sethi, V.K.; Wright, I.G. Evaporator Tube Wastage and Chlorine, pp. 417-423, in Chlorine in Coal, ed. J. Stringer and D. D. Banerjee, Elsevier, N.Y., 1991.

10. MacAdam, S.S.; Stringer, J.; Levy, A. A Novel Laboratory Test Procedure for Studying In-Bed Erosion - Design and Some Early Results, Proc. 10th Int. Conf. on Fluidized Bed Combustion, p. 937, San Francisco, California, April 1990.

11. MacAdam, S.S.; Stringer, J. The Nature of Bubble-Induced Wear of In-Bed Tubes in FBCs, Proc. 4th Berkeley Conf. on Corrosion-Erosion-Wear of Materials at Elevated Temperatures, Berkely, CA, Jan. 1990, ed. A. Levy, p. 17-1.

12. MacAdam, S.S.; Stringer, J. Development of a Unique Laboratory Scale Fluidized Bed Wear Testing Unit, Wear, v. 135, p. 403-422, 1990.

13. Olowson, P.A.; Almstedt, A.E. Influence of pressure and fluidization velocity on the bubble behavior and gas flow distribution in a fluidized bed, Chemical Engineering Science, v. 45, p. 1733-1741, 1990.

14. Tsutsumi, K.;Taebayashi, J.;Hasegawa, K.;Takamori, M.;Okada, Y.; Furubayshsi, K. Development of erosion resistant in-bed tubes, report from Kawasaki Heavy Industries, Ltd. Akashi-City, Japan, 1988.

15. Dennis, R.A. Wear of 6061 aluminum test specimens during an in-bed exposure to an AFB cold model environment, Wear, v. 131, p. 241-250, 1989.

16. Kennedy, T.C. A study of forces on immersed tubes in fluidized bed, EPRI CS-1542, Project 718-2, Topical Report, 1980.

17. Jansson, S.A. Tube wastage mechanisms in fluidized bed combustion systems, Proc. int. Conf. on Fluidized Bed Combustion, Houston, TX, March 18-21, 1985, DOE/NETC-85/6021, p. 750-759, 1985.

18. Hosny, H.; Grace, J.R. Forces on a tube immersed within a fluidized bed, Proc. 4th Int. Conf. on Fluidization, Kashikojima, Japan, May 29-June 3, 1983, ed. Daizo Kunii and Ryozo Toei, Jap. Soc. Chem. Eng, Engineering Foundation, p. 111-120, 1984.

19. Jansson, S.A. Videotape shown at EPRI Workshop on FBC Materials Issues, Port Hawkesbury, Nova Scotia, August 1985.

20. Parkinson, M.J. Work conducted at British Coal/Coal Research Establishment, Stoke Orchard, U.K.

21. Hou, P.Y.; MacAdam, S.;Zhang, H.; Stringer, J. Summary of Results from the Berkeley In-Bed Tube Erosion Simulator, Mater. at High Temp., v. 14, n. 3, p. 325-335, 1997.

22. MacAdam, S.S.; Stringer, J. Particle impact and impact distribution within a fluidized bed combustor environment, Wear, v. 141, p. 373-394, 1991.

23. MacAdam, S.S. Mechanisms of oxidation/3-body abrasion in steels, M. S. Thesis, Material Science Departement, University of California, Berkeley, 1993.

24. MacAdam, S.S.; Stringer, J. Temperature dependence of steel wastage in a bubbling fluidized bed simulator", Corrosion, v. 49, p. 156-169, 1993.

25. Zhang, H.; Hou, P.Y.; Stringer, J. The effect of temperature gradient on steel tube wastage in a bubbling fluidized bed simulator", Wear, v. 197, p. 286-294, 1996.

26. Hou, P.Y.; Zhang, H.; Stringer, J. Strong HCl Effect on Tube Wastage in a Simulated Bubbling Fluidized Bed Environment, Wear, v. 237, p. 137-139, 2000.

27. Stringer, J.; Wright, I.G. Erosion/Corrosion in FBC Boilers, Proc. of a Workshop held at Argonne National Laboratory, Argonne, IL, November 2-6, p. 1.1-1.38, 1987.

28. MacAdam, S.S.; Stringer, J. The circumferential distribution of wastage on in-bed tubes in fluidized bed combustors, Wear, v. 186-187, p. 325-331, 1995.

29. Stringer, J.; MacAdam, S.S.; Wright, I.G.; Sethi, V.K. In-bed wastage of tubes in bubbling fluidized bed combustors: qualification criteria for laboratory test procedures, $3^{\text {rd }}$ International Symposium on High Temperature Corrosion, Les Embiez, France, May 25-29, 1992, J. de Physique IV, v. 3, p. 797-805, 1993.

30. Levy, A.V. The erosion of metal alloys and their scales, Proc. Corrosion-Erosion-Wear of Materials in Emerging Fossil Energy Systems, Berkeley, CA, Jan. 27-29, p. 298-376, 1982.

31. Stringer, J. Corrosion, erosion and erosion-corrosion of in-bed components in influidized bed combustion, Corroion 86, paper no. 90, Houston, Texas, March 17$21,1986$. 
32. Rishel, D.M.; Pettit, F.S.; Birks, N. Some Principal Mechanisms in the Simultaneous Erosion and Corrosion Attack of Metals at High Temperature, Proc. of Conference on Erosion-Corrosion-Wear of Materials at Elevated Temperatures, ed. A. V. Levy, NACE, Houston, TX, 1991, paper no. 16.

33. Bragg, L.J.; Finkelman, R.B.; Tewalt, S.J. Distribution of Chlorine in United States Coal, pp. 3-10, in Chlorine in Coal, ed. J. Stringer and D. D. Banerjee, Elsevier, N.Y., 1991.

34. Gluskoter, H.J. Chlorine in Coals of the Illinois Basin, Trans. Mining Engineering, p. 373-379, 1967.

35. Chou, C.L. Distribution and Forms of Chlorine in Illinois Basin Coals, p. 11-29, Chlorine in Coal, ed. J. Stringer and D. D. Banerjee, Elsevier, N.Y., 1991.

36. Herod, A.A.; Hodges, N.J.; Pritchard, E.; Smith, C.A. Mass Spectrometric Study of the Release of $\mathrm{HCl}$ and Other Volatiles from Coals During Mild Heat Treatment, Fuel, v. 62, p. 1331-1336, 1983.

37. Gibb, W.H. in Corrosion Resistant Materials for Coal Conversion Systmes, ed. D. B. Meadowcroft and M. I. Manning, Applied Science, London, p. 25, 1983.

38. Hou, P.Y.; Niu, Y.; Sum, T.J.; Stringer, J. Effect of $\mathrm{HCl}$ on the Corrosion and Wear of in-bed Tubes in a Laboratory Simulated Bubbling Fluidized Bed, Wear, v. 235, p. 635-646, 1999.

39. Hou, P.Y.; Sum, T.J.; Niu, Y.; Stringer, J. HCl Effect on
In-Bed Tube Wastage in Bubbling Fluidized Bed, a Laboratory Study Under Simulated Dense Particle Impact Condition, paper no. 137, Proc. 15th International Conference on Fluidized Bed Combustion, ed. R. B. Reuther, ASME, N.Y., 1999.

40. Bruce, D.; Hancock, P. Influence of Mechanical Properties of Surface Oxide Films on Oxidation Mechnisms. Pt. 1. A Vibrational Technique to Study the Nature and Growth of Thermally Formed Oxide Films on Metals, J. Inst. Met., v. 97, p. 140-148, 1969.

41. Rhee, M.H.; McNallan, M.J.; Rothman, M.F. Long Term High Temperature Corrosion Studies of High Temperature Alloys in Chlorine Contaminated Environments, J. Materials for Energy Systems, v. 7, p. 294-301, 1986.

42. Reese, E.; Grabke, H.J. Effects of Chlorides on the Oxidation of the $2.25 \mathrm{Cr}-1 \mathrm{Mo}$ Steel, Werkstoffe u. Korr., v. 43, p. 547-557, 1992.

43. Hou, P.Y.; Stringer, J. A Study of the Apparent Detrimental Effect of a Surface Applied $\mathrm{HfO}_{2}$ Coating on the Oxidation Behavior of Alloys, J. of Electrochem. Soc., v. 138, p. 327-328, 1990.

44. James, P.J.; Pinder, L.W. Effect of Coal Chlorine on the Fireside Corrion of Boiler Furnace Wall and Superheater/Reheater Tubing, Mater. at High Temp., v. 14, p. 187-196, 1997.

45. Schutze, M. Plasticity of Protective Oxide Scales, Mater. Sci. Technol., v. 6, p. 32-38, 1990. 